\title{
THE INFLUENCE OF THE SIZE OF HEMATITE PARTICLES ON THE PROPERTIES OF POLYETHYLENE/HEMATITE COMPOSITES
}

\author{
${ }^{1}$ Ana PERŠIĆ, ${ }^{2}$ Nina POPOV, ${ }^{1} E$ Iza ŠTEFANOVIĆ, ${ }^{2}$ Stjepko KREHULA, \\ ${ }^{1}$ Emi GOVORČIN BAJSIĆ, 'Mirela LESKOVAC, 'Ljerka KRATOFIL KREHULA \\ ${ }^{1}$ Faculty of Chemical Engineering and Technology, University of Zagreb, Zagreb, Croatia, EU, \\ apersic@fkit.hr, estefanov@fkit.hr, egovor@fkit.hr, mlesko@fkit.hr, krehula@fkit.hr \\ ${ }^{2}$ Division of Materials Chemistry, Ruđer Bošković Institute, Zagreb, Croatia, EU, \\ Nina.Popov@irb.hr, krehul@irb.hr
}

https://doi.org/10.37904/nanocon.2021.4330

\begin{abstract}
The incorporation of metal oxide particles into polymer matrix in many cases leads to improved characteristics of the material: thermal stability, mechanical strength, light absorbing or antibacterial properties etc.

This study aims to develop polyethylene/hematite composites prepared with hematite $\left(\alpha-\mathrm{Fe}_{2} \mathrm{O}_{3}\right)$ particles of different size. Such types of composites have not been yet thoroughly studied but have a potential to reveal improved properties in comparison to the pure polymer. Polyethylene is a material with a broad field of application, primarily as packaging material for food and other products. Hematite is non-toxic, thermally and chemically stable low-cost metal oxide. There is also a demanding task to prepare composites with nonaggregated hematite particles and their fine dispersion in polyethylene matrix.

In this work two types of hematite with well-defined shape and uniform size were used for preparation of the composites: hematite $\mathrm{HC} 1$ with cubic particles of average size of $2 \mu \mathrm{m}$ and HS2 with spherical particles sized of about $100 \mathrm{~nm}$. The mass fraction of hematite in the composites was $0.25,0.5$ and $1 \%$. Prepared polyethylene/hematite composites were characterized by thermogravimetric analysis (TGA), differential scanning calorimetry (DSC) and diffuse reflectance UV-Vis-NIR spectroscopy. The mechanical properties were also studied. The results show that such composites have improved properties in comparison to a pure polyethylene, especially the composites with hematite HS2 due to its particles of lower size and large surface. Obtained results reveal that such composites may be a promising material for wide range of applications.
\end{abstract}

Keywords: Composites, polyethylene, hematite, thermal stability, UV blocking

\section{INTRODUCTION}

An increase in the use of polymer materials recently demands their new or improved types and roles in many different fields. Polymer composites represent an outstanding choice for development of materials because they unite the properties of polymer matrix and filler which will ultimately result with completely new or improved material types. Fillers are usually used to improve polymer's properties, especially mechanical properties, or to replace the part of polymer matrix with less expensive substance. Furthermore, fillers are nowadays also used to develop some functional properties of polymer composites: UV blocking, water absorbtion, flavour releasing, oxygen scavenging, antimicrobial activity etc. The choice of additives must especially take care of health and safety, i.e. it demands the use of nontoxic components [1]. Hematite $\left(\alpha-\mathrm{Fe}_{2} \mathrm{O}_{3}\right)$ represents good option for application in preparation of polymer composites due to its non-toxicity, thermal and chemical stability, low cost and ageing resistance. Because of such suitable properties, the polymer/hematite composites may possess improved thermal, mechanical and magnetic properties as well as catalytic characteristics [2]. Development of advanced functional polymer materials includes sometimes additives that 
contribute to improved UV blocking property, which is very important in prevention of material's degradation and in prolonging its lifetime [3]. To obtain a composite material with good and balanced properties, it is very important to use the filler with the particles of uniform shape and size as well as to avoid their aggregation in the polymer matrix. This study aims to develop polyethylene/hematite composites with the hematite particles of different size and to analyze their influence on the overall composite properties. The reason for this research was also that polyethylene/hematite composites have not been yet thoroughly studied but their development may be a promising choice for creation of polymer materials with advanced applications.

\section{EXPERIMENTAL PART}

\subsection{Materials}

For the preparation of the polyethylene/hematite composites LDPE polymer granulate (Dow Chemical) was used. Hematite particles HC1 and HS2 were synthesized in Laboratory for Synthesis of New Materials, Division of Materials Chemistry, Ruđer Bošković Institute. Uniform hematite particles were prepared according to slightly modified synthesis procedure reported by Sugimoto et al. [4]. For preparation of cubic hematite particles (sample $\mathrm{HC} 1$ ) $2.5 \mathrm{ml}$ of $\mathrm{H}_{2} \mathrm{O}$ and $47.5 \mathrm{ml}$ of $6 \mathrm{M} \mathrm{NaOH}$ aqueous solution were slowly added to $50 \mathrm{ml}$ of $2 \mathrm{M} \mathrm{FeCl}_{3}$ aqueous solution in a polypropylene (PP) bottle under the strong magnetic stirring. Obtained suspension was heated at $100{ }^{\circ} \mathrm{C}$ in laboratory oven for 8 days. For preparation of spherical hematite particles (sample HS2) $2.2 \mathrm{ml}$ of $\mathrm{H}_{2} \mathrm{O}, 1.5 \mathrm{ml}$ of $1 \mathrm{M} \mathrm{Na}_{2} \mathrm{SO}_{4}$ aqueous solution and $46.3 \mathrm{ml}$ of $6 \mathrm{M} \mathrm{NaOH}$ aqueous solution were slowly added to $50 \mathrm{ml}$ of $2 \mathrm{M} \mathrm{FeCl}_{3}$ aqueous solution in a PP bottle under the strong magnetic stirring. Obtained suspension was heated at $100^{\circ} \mathrm{C}$ in laboratory oven for 6 days. Precipitated hematite particles were washed (using milli-Q water and centrifuge) and dried at $60^{\circ} \mathrm{C}$ in air.

SEM images of the synthesized hematite samples HC1 and HS2 were recorded using a field emission scanning electron microscope (FE-SEM) model JSM-7000F manufactured by Jeol Ltd. They are presented in Figures 1 and 2. Hematite $\mathrm{HC} 1$ has cubic particles of average size of $2 \mu \mathrm{m}$ while HS2 has spherical particles sized of about $100 \mathrm{~nm}$.

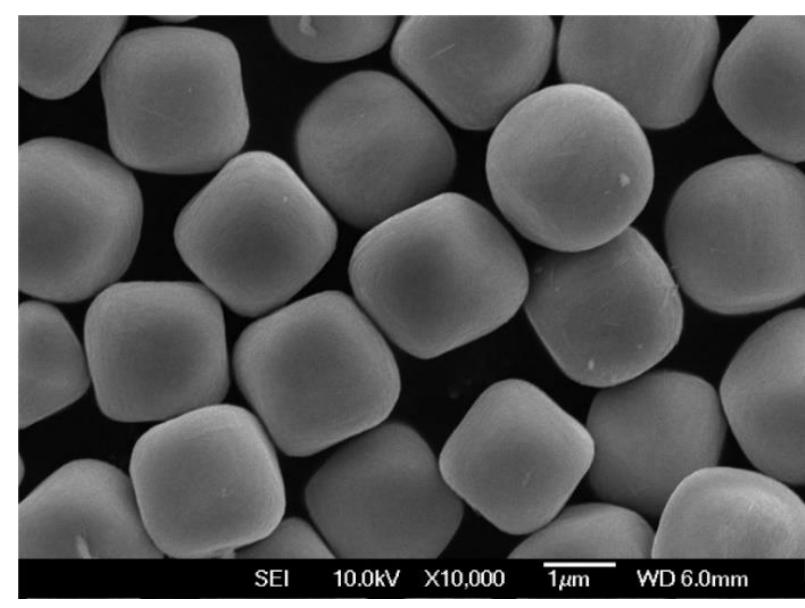

Figure 1 SEM image of hematite sample HC1

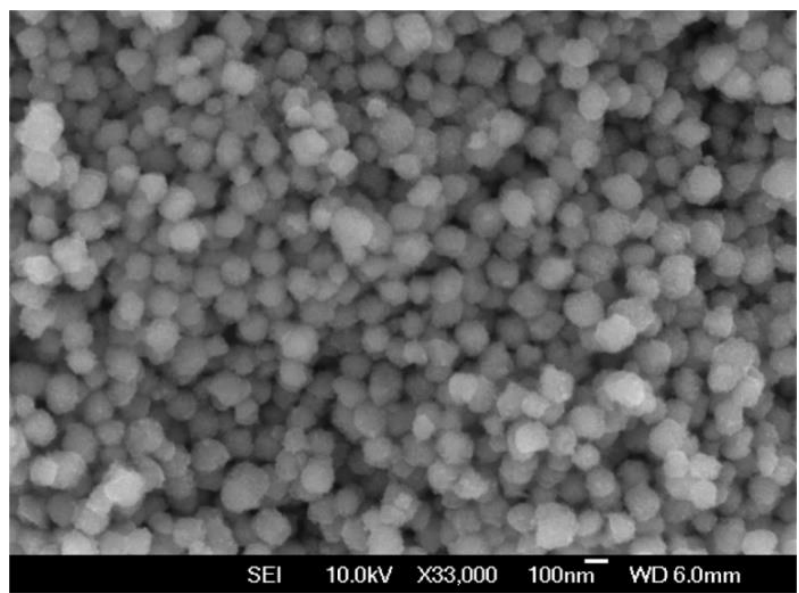

Figure 2 SEM image of hematite sample HS2

\subsection{Preparation of the composites}

Polyethylene/hematite composites denoted as LDPE/HC1 and LDPE/HS2 are prepared by mixing in a Brabender kneader, at $180^{\circ} \mathrm{C}$ over a period of 3 minutes, $45 \mathrm{rpm}$. The content of hematite in the samples was $0.25,0.5$ and $1 \%$. The obtained composite materials were prepared for further characterization by pressing into the foils and plates. The pressing was carried out by hydraulic press Dake, model 44-226 at a temperature of $190^{\circ} \mathrm{C}$. 


\subsection{Characterization}

UV-Vis-NIR spectroscopy. Diffuse reflectance UV-Vis-NIR spectra of polymer composite films were recorded at $20{ }^{\circ} \mathrm{C}$ using a Shimadzu UV-3600 UV-Vis-NIR spectrophotometer with integrating sphere. Barium sulfate was used as a reference material.

Thermogravimetric analysis (TGA). The thermal stability of the obtained polymer composites was determined by the thermogravimetric analyzer TA Instruments Q500. Mass specimens of $10 \mathrm{mg}$ were analyzed in the nitrogen stream at a heating rate of $10^{\circ} \mathrm{C} / \mathrm{min}$ in the temperature range of 25 to $800{ }^{\circ} \mathrm{C}$.

Differential scanning calorimetry (DSC). The thermal properties were determined on Mettler Toledo DSC822e device. Samples were heated from $25^{\circ} \mathrm{C}$ to $180^{\circ} \mathrm{C}$ and then they were cooled down to $-150{ }^{\circ} \mathrm{C}$ (heating/cooling rate was $10^{\circ} \mathrm{C} / \mathrm{min}$ ), two heating and cooling cycles were performed.

Determination of mechanical properties. Mehanical properties were determined on Zwick 1445 universal device. Samples were $100 \mathrm{~mm}$ long and $10 \mathrm{~mm}$ wide ( 1mm thick). The stretching speed was $50 \mathrm{~mm} / \mathrm{min}$.

\section{RESULTS}

\subsection{UV/Vis spectroscopy}

Ultraviolet (UV) radiation induces harmful influences to polymer materials. It may significantly reduce the properties and lifetime of polymers. In order to prevent such degradation effects, different types of UV stabilizers must be used. Some of them include metal oxides like titanium or zinc oxide. There is also a potential of hematite to act as an UV stabilizer i.e. UV blocking agent due to its UV absorption capability [5]. From UVVis-NIR spectra of polyethylene/hematite, Figures $\mathbf{3}$ and $\mathbf{4}$, it can be seen that some differences are observed in comparison with the pure polyethylene. The composites show absorption in ultraviolet region and in the visible light region. The particles of lower size (HS2), due to their large surface, enhance the UV absorbance capacity of the composites. For that reason, such prepared polyethylene/hematite composites may be considered as suitable materials for making different packaging types with good UV blocking properties.

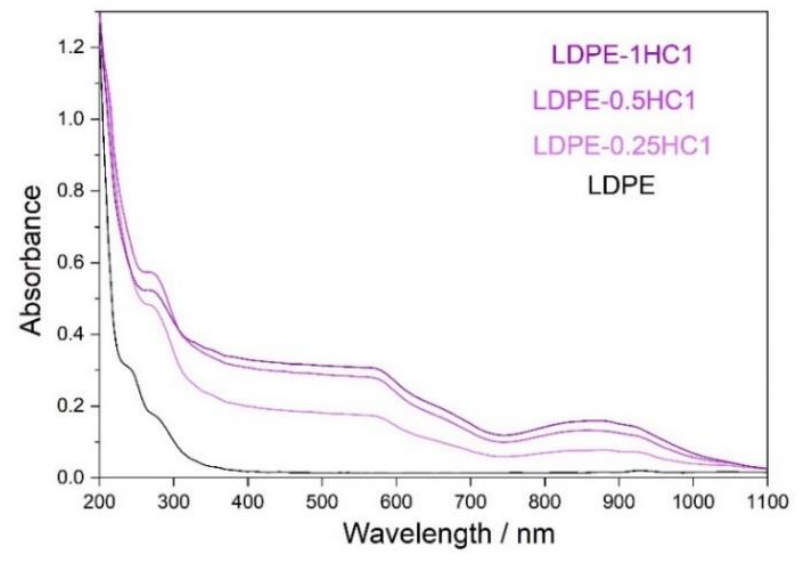

Figure 3 UV/Vis spectra of LDPE and LDPE/HC1 composites

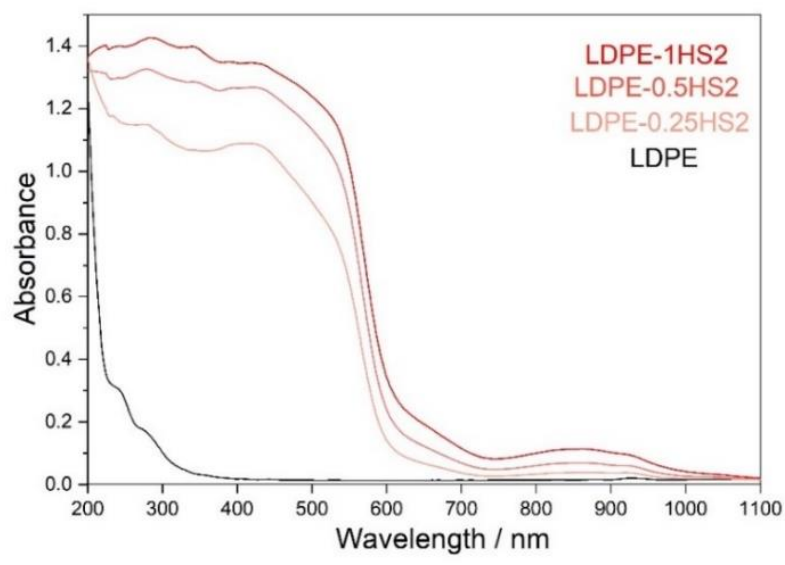

Figure 4 UV/Vis spectra of LDPE and LDPE/HS2 composites

\subsection{Thermogravimetric analysis}

It is known that hematite may improve the thermal stability of some types of polymers e. g. polystyrene [6] but there is a lack of information regarding use of hematite in polyethylene matrix. For that reason, this study brings the results of the thermogravimetric analysis of polyethylene/hematite composites, presented in Table 1. 
Table 1 Initial decomposition temperature of the samples ( $\left.T_{95 \%}\right)$ and temperature of maximum rate of decomposition ( $\left.T_{\max }\right)$.

\begin{tabular}{|c|c|c|}
\hline Sample & $\begin{array}{c}\mathbf{T}_{95 \%} \\
\left({ }^{\circ} \mathbf{C}\right)\end{array}$ & $\begin{array}{c}\text { Tmax } \\
\left({ }^{\circ} \mathbf{C}\right)\end{array}$ \\
\hline LDPE & 422.60 & 467.07 \\
\hline LDPE $+0,25 \%$ HC1 & 421.88 & 466.35 \\
\hline LDPE $+0,5 \%$ HC1 & 419.01 & 467.07 \\
\hline LDPE $+1 \%$ HC1 & 426.16 & 468.67 \\
\hline LDPE $+0,25 \%$ HS2 & 438.39 & 487.35 \\
\hline LDPE $+0,5 \%$ HS2 & 407.53 & 483.57 \\
\hline LDPE $+1 \%$ HS2 & 436.23 & 491.46 \\
\hline
\end{tabular}

The results show that LDPE is degraded in one step. Samples of LDPE/hematite composites also degrade in one step but on higher temperatures, what proves improvement of their thermal stability in comparison to the pure LDPE. LPDE composites with HS2 (hematite particles of smaller size, average size of about $100 \mathrm{~nm}$ ) showed a significant increase of $\mathrm{T}_{95 \%}$ and $\mathrm{T}_{\max }$. $\mathrm{T}_{95 \%}$, which is the temperature at which 5 mas. $\%$ of the sample is decomposed (initial decomposition temperature), is improved even up to $16{ }^{\circ} \mathrm{C}$. The temperature of maximum rate of decomposition, $T_{\max }$, for that composites, is also improved (even up to $24{ }^{\circ} \mathrm{C}$ ) compared to the pure LDPE.

\subsection{Differential scanning calorimetry (DSC)}

The results of DSC analysis, presented in Table 2, show that LDPE is a crystalline polymer with a glass transition of $-129.75^{\circ} \mathrm{C}$. The addition of hematite to the LDPE matrix leads to a slight increase in the degree of crystallinity. The increase in the degree of crystallinity can be attributed to the action of filler as a nucleating agent [7].

Table 2 The results of the analysis by differential scanning calorimetry

\begin{tabular}{|c|c|c|c|c|c|}
\hline Sample & $\begin{array}{c}\mathbf{T}_{\mathbf{g}} \\
\left({ }^{\circ} \mathbf{C}\right)\end{array}$ & $\begin{array}{c}\mathbf{T}_{\mathbf{m}} \\
\left({ }^{\circ} \mathbf{C}\right)\end{array}$ & $\begin{array}{c}\Delta \mathbf{H}_{\mathbf{m}} \\
\left(\mathbf{J g}^{-1}\right)\end{array}$ & $\begin{array}{c}\mathbf{T}_{\mathbf{c}} \\
\left({ }^{\circ} \mathbf{C}\right)\end{array}$ & $\begin{array}{c}\mathbf{X}_{\mathbf{c}} \\
(\%)\end{array}$ \\
\hline LDPE & -129.75 & 114.41 & -86.91 & 96.08 & 29.66 \\
\hline LDPE + 0,25\% HC1 & -123.07 & 111.84 & -111.46 & 95.24 & 38.14 \\
\hline LDPE + 0,5\% HC1 & -130.55 & 112.00 & -91.83 & 95.31 & 31.50 \\
\hline LDPE + 1\% HC1 & -131.86 & 112.44 & -97.85 & 94.88 & 33.73 \\
\hline LDPE + 0,25\% HS2 & -128.02 & 112.50 & -115.87 & 95.22 & 39.64 \\
\hline LDPE + 0,5\% HS2 & -126.72 & 111.88 & -109.76 & 95.12 & 37.65 \\
\hline LDPE + 1\% HS2 & -125.84 & 111.99 & -111.91 & 95.59 & 38.58 \\
\hline
\end{tabular}

\subsection{Determination of mechanical properties}

Hematite may significantly improve the mechanical properties of some types of polymer matrix [8]. The results of the mechanical properties of LDPE and the composite samples, expressed as dimensionless tensile strength and dimensionless elongation at break, are presented in Figures $\mathbf{5}$ and $\mathbf{6}$. Mechanical properties show the improvement of the tensile strength for all composite samples in comparison to the pure LDPE. The elongation at break is improved for the samples LDPE $+1 \% \mathrm{HC} 1$ and LDPE $+0.25 \% \mathrm{HS} 2$. 


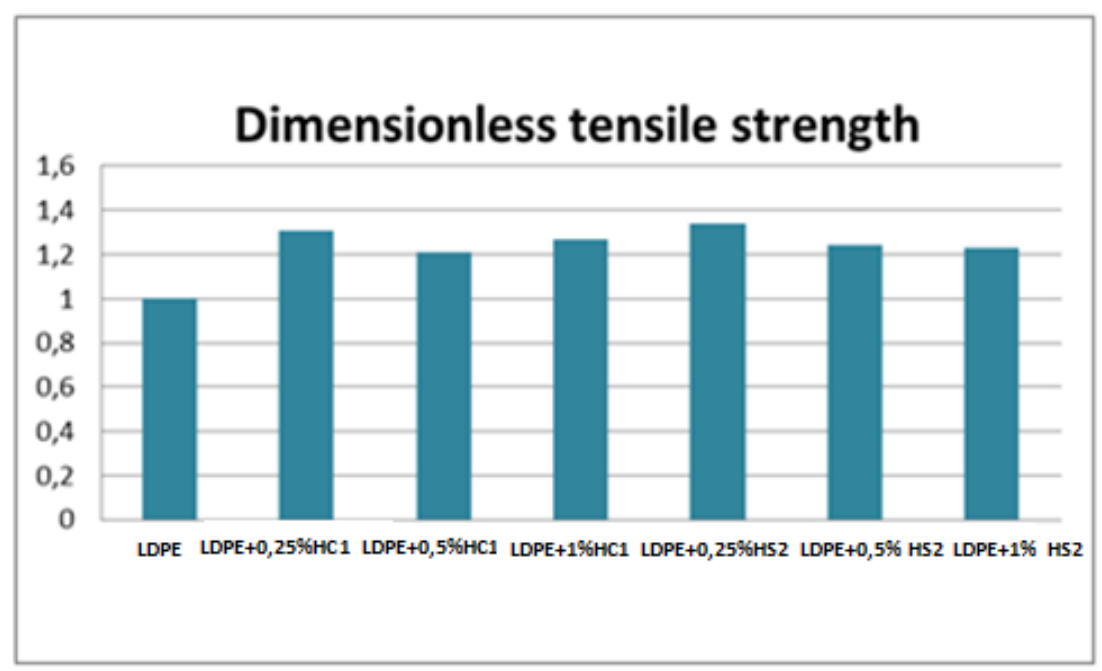

Figure 5 Tensile strength of the studied samples

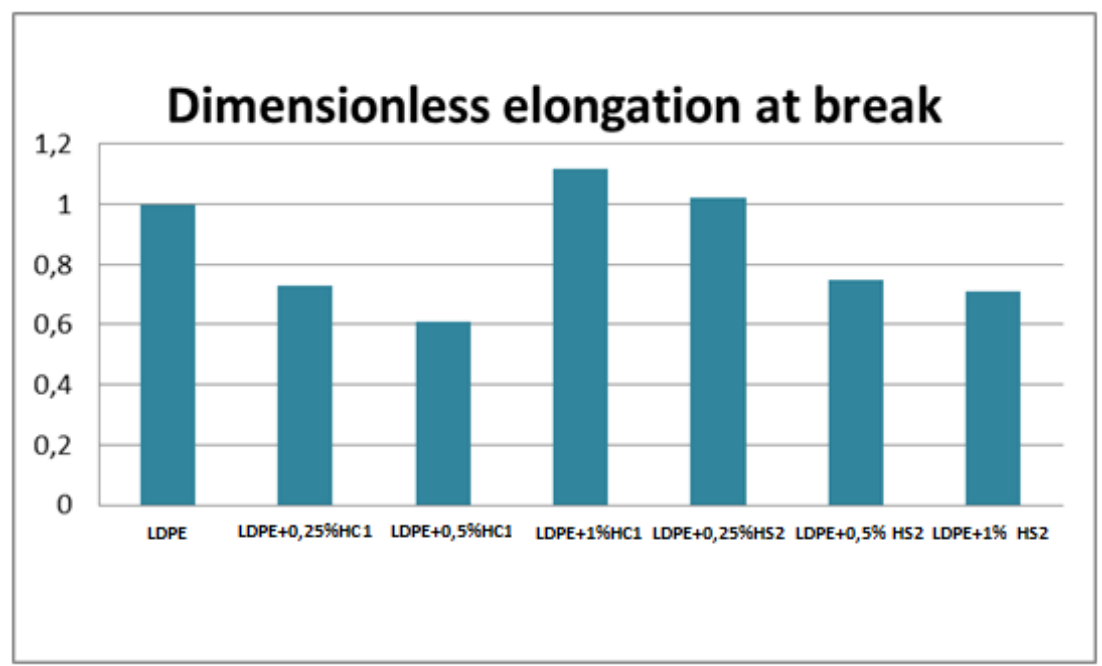

Figure 6 Elongation at break of the studied samples

\section{CONCLUSION}

The results of UV-Vis-NIR absorption measurements show that all prepared composites (LDPE/HC1 and LDPE/HS2) are suitable for making different packaging materials with good UV blocking properties. The LDPE $+0.25 \%$ HS2 composite can be considered as the most thermally stable sample because it shows high temperature stability despite the low filler content.

The results show that LDPE/hematite composites have improved UV blocking, thermal and mechanical properties in comparison to a pure polyethylene, especially the composites with hematite HS2 due to its particles of lower size and large surface. Such composites may be a promising material for wide range of applications.

\section{ACKNOWLEDGEMENTS}

The part of this research (the synthesis of hematite particles) was supported by the Croatian Science Foundation, project number IP-2016-06-8254. 


\section{REFERENCES}

[1] LLORENS, A., LLORET, E., PICOUET, P.A., TRBOJEVICH, R., FERNANDEZ, A. Metallic-based micro and nanocomposites in food contact materials and active food packaging. Trends in Food Science \& Technology. 2012, vol. 24, pp. 19-29.

[2] KAUSAR, A. Polymeric materials filled with hematite nanoparticle: current state and prospective application. Polymer-Plastics Technology and Materials. 2020, vol. 59, no. 3, pp. 1-16.

[3] HRNJAK-MURGIĆ, Z., REŠČEK, A. PTIČEK SIROČIĆ, A., KRATOFIL KREHULA, Lj., KATANČIĆ, Z. Nanoparticles in Active Polymer Food Packaging. Surrey: Smithers Pira, 2015.

[4] SUGIMOTO, T., SAKATA, K. Preparation of monodisperse pseudocubic $\alpha-\mathrm{Fe}_{2} \mathrm{O}_{3}$ particles from condensed ferric hydroxide gel. Journal of Colloid and Interface Science. 1992, vol. 152, no. 2, pp. 587-590.

[5] TRUfFAUlT, L., CHOQUENET, B., KONSTANTINOV, K., DEVERS, T., COUTEAU, C., COIFFARD, L. J. M. Synthesis of Nano-Hematite for Possible Use in Sunscreens. Journal of Nanoscience and Nanotechnology. 2011, vol. 11, pp. 2413-2420.

[6] KULJANIN, J., MARINOVIĆ CINCOVIĆ, M., ZEC, S., ČOMOR, M. I., NEDELJKOVIĆ, J. M. Influence of Fe $\mathrm{O}_{3}$ filler on the Thermal Properties of Polystyrene. Journal of Materials Science Letters. 2003, vol. 22, pp. $235-237$.

[7] ZALDUA, N., MAIZ, J., de la CALLE. A., GARCÍA-ARRIETA, S., ELIZETXEA, C., HARISMENDY, I., TERCJAK, A., MÜLLER, A. J. Nucleation and Crystallization of PA6 Composites. Polymers. 2019, vol. 11, pp. 1680-1699.

[8] DJOKOVIĆ, V.; NEDELJKOVIĆ, J. M. Stress Relaxation in Hematite Nanoparticles Polystyrene Composites. Macromolecular Rapid Communications. 2000, vol. 21, pp. 994-997. 